Rev. Int. Contam. Ambie. 35 (3) 575-588, 2019

DOI: 10.20937/RICA.2019.35.03.05

\title{
DEGRADACIÓN DE LA MEZCLA COMERCIAL DE LOS HERBICIDAS ATRAZINA Y AMETRINA, UTILIZANDO CULTIVOS CON CÉLULAS EN SUSPENSIÓN E INMOVILIZADAS
}

\author{
Biodegradation of the commercial mixture of the herbicides atrazine and ametryn, \\ using cultures with suspended and immobilized cells \\ Karla Lizzette CASTILLO-MARTÍNEZ, Deifilia AHUATZI-CHACÓN*, Nora RUIZ-ORDAZ, \\ Carlos Alberto SANDOVAL-CARRASCO, Cleotilde JUÁREZ-RAMÍREZ, \\ Juvencio GALÍNDEZ-MAYER y Angélica María SALMERÓN-ALCOCER
}

Laboratorio de Biotecnología, Departamento de Ingeniería Bioquímica, Instituto Politécnico Nacional, Escuela Nacional de Ciencias Biológicas, Av. Wilfrido Massieu s/n, Zacatenco, 07738 Ciudad de México, México

*Autora de correspondencia: dahuatzi@hotmail.com

(Recibido enero 2018; aceptado septiembre 2018)

Palabras clave: quimiostato, biobarrera, comunidad microbiana, biopelícula

\begin{abstract}
RESUMEN
El empleo desmedido de los herbicidas ha ocasionado que las malezas generen resistencia a estos agroquímicos, por lo que se ha implementado el uso de mezclas para garantizar su efecto sobre diversos pastos indeseables. Una de las formulaciones comerciales utilizada en México es la mezcla de atrazina con ametrina. La información sobre procesos de degradación de la ametrina es escasa y prácticamente no hay referencias sobre la biodegradación de la mezcla comercial de la atrazina con ametrina. En este trabajo se presenta la biodegradación de esta mezcla comercial utilizando una comunidad microbiana en diferentes tipos de cultivo, empleando un quimiostato y una biobarrera. Para evaluar la capacidad de degradación de la comunidad microbiana se utilizaron células planctónicas en un sistema por lote semicontinuo, donde se obtuvo la remoción completa de ambos herbicidas. A partir de este sistema se inició un proceso continuo en el que, con todas las cargas volumétricas probadas, se removió el $100 \%$ de ametrina y más del $97 \%$ de atrazina. Durante la operación del proceso continuo se observó la formación de biopelícula en las paredes del reactor, por lo que se decidió utilizar una biobarrera con fragmentos de roca volcánica (tezontle) como soporte. En este sistema se obtuvieron eficiencias (n) y velocidades volumétricas de remoción $\left(\mathrm{R}_{\mathrm{V}}\right)$ de los herbicidas, del $100 \%$ y $287 \mathrm{mg} / \mathrm{L} / \mathrm{d}$, respectivamente. En todos los cultivos evaluados se observó la acumulación de ácido cianúrico; sin embargo, a bajas cargas volumétricas se alcanzó una degradación considerable de este intermediario metabólico.
\end{abstract}

Key words: chemostat, biobarrier, microbial community, biofilm

\begin{abstract}
The excessive use of herbicides has caused weeds resistance to these compounds; thus, it has been implemented the use of mixtures of herbicides to ensure its effect on weeds. One of the commercial mixtures used in Mexico is that of atrazine and ametryn.
\end{abstract}


Information on processes for ametryn degradation is scarce, and virtually no references to the biodegradation of the commercial mixture of atrazine and ametryn exist. In this study, the biodegradation of this commercial mixture using a microbial community in different types of cultures, and using a chemostat and biobarrier is presented. To assess the degradation capability of the microbial community, planktonic cells were used in a semi-continuous batch system. From this system, the continuous process was started. In repeated batch cultures, complete removal of both herbicides was obtained. In the continuous system, at all tested volumetric loads, the removal efficiencies of ametryn and atrazine were of 100 and $97 \%$ respectively. During continuous operation, biofilm formation on the reactor walls was observed; thus, it was decided to install a biobarrier using volcanic rock fragments (tezontle) as biofilm support. In this system, the removal efficiencies ( $\mathrm{y})$ and the volumetric removal rates (Rv) of the herbicide mixture were $100 \%$ and $287 \mathrm{mg} / \mathrm{L} / \mathrm{d}$, respectively. At all the loading rates tested, cyanuric acid accumulation was observed; however, when the biobarrier was operated at low volumetric loading rates, considerable metabolic degradation of this intermediate was achieved.

\section{INTRODUCCIÓN}

El control de malezas es una práctica obligada en la agricultura para evitar daños importantes en los cultivos, se ha estimado que la presencia de malezas ocasiona pérdidas anuales del orden de dos billones de toneladas de alimentos en Latinoamérica (Sattin y Berti 2004). Las malezas son especies de plantas no deseadas que compiten con las plantas cultivables por los nutrientes del suelo, agua y luz; además, al momento de la cosecha las semillas de las malezas contaminan la producción obtenida, reduciendo la eficiencia de la fertilización y la irrigación y facilitando el aumento de la densidad de otras plagas, con lo que finalmente los rendimientos agrícolas y su calidad disminuyen severamente. Un método químico que ha resultado efectivo para el control de las malezas en las últimas décadas es el uso de herbicidas.

El control químico de las malezas requiere conocer las especies presentes y su nivel de infestación; en el caso de las especies anuales, una estrategia elemental es aplicar herbicidas residuales que cubran todo el espectro de malezas presentes, como es el caso de la atrazina (Olea et al. 2009). La atrazina es el herbicida triazínico más utilizado a nivel mundial para controlar una variedad de malezas de hoja ancha, principalmente en cultivos de maíz, sorgo, caña de azúcar y suelos no cultivados (Pussemier et al. 1997, Jacobsen et al. 2001, Ralebitso et al. 2002, Strong et al. 2002, Hansen et al. 2013, Domínguez-Garay et al. 2016, Sun et al. 2017, Rimayi et al. 2018, Singh et al. 2018, Yu et al. 2018). Para un control más efectivo de algunas gramíneas difíciles, es usual la aplicación de la mezcla con ametrina en pre emergencia y en post emergencia temprana (IRET 2018). La ametrina es un herbicida metiltio triazínico selectivo, que en mezcla con la atrazina previene posteriores emergencias de malezas anuales. La acción del herbicida comercial, utilizado en el presente trabajo, que contiene la mezcla de estos dos ingredientes activos, la atrazina más la ametrina, se basa en el bloqueo de la fotosíntesis y reúne el efecto por absorción de la atrazina a través de la raíz, con el efecto de contacto de la ametrina. Por lo tanto, se utiliza para combatir las malezas presentes y para evitar nuevos brotes. Esta mezcla comercial de herbicidas proporciona a los cultivos un control de malezas prolongado por lo cual se aplica, entre otros, en plantillas de caña de azúcar que requieren un periodo largo libre de malezas. La atrazina proporciona el efecto residual y la ametrina el efecto contra la maleza presente (IRET 2018).

Aunque es cierto que el éxito en la agricultura actual se debe en gran medida al uso de los herbicidas, su empleo indiscriminado ha tenido un impacto negativo sobre el ambiente y la salud de los agricultores y los consumidores. La atrazina y la ametrina están clasificadas por la Organización Mundial de la Salud (OMS) dentro del grupo III, ligeramente peligroso y por la Agencia de Protección al Ambiente de los EUA (USEPA) dentro del grupo III, ligeramente tóxico para la salud humana, con una dosis letal media/concentración letal media (DL50/CL50) oral en ratas de $1869-3090 \mathrm{mg} / \mathrm{kg}$ para la atrazina (WHO 2011) y de $1009-1356 \mathrm{mg} / \mathrm{kg}$ para la ametrina (USEPA 2005). Ambos herbicidas son muy tóxicos para organismos acuáticos; presentan una toxicidad aguda muy alta en peces, con una CL50 (96 h) en trucha arco iris de 4.5 $\mathrm{mg} / \mathrm{L}$ para la atrazina y de $5 \mathrm{mg} / \mathrm{L}$ para la ametrina; toxicidad alta en anfibios y toxicidad extrema en plantas, como en el helecho acuático y algas, con una concentración efectiva media (CE50) (72 h) en Scenedesmus subspicatus de $0.043 \mathrm{mg} / \mathrm{L}$ para atrazina y una CE50 
(72 h) en Raphidocelis subcapitata de $0.0036 \mathrm{mg} / \mathrm{L}$ para ametrina. La atrazina está incluida en la lista de sustancias de disruptores endocrinos (Kucka et al. 2012).

El uso excesivo de estos agroquímicos ha provocado, por filtración o escorrentías, la progresiva contaminación de los cuerpos de agua, se ha detectado contaminación por atrazina en agua de lluvia, aguas subterráneas, superficiales y aguas para consumo humano (Kontchou y Gschwind 1999, Jacobsen et al. 2001, Sun et al. 2017, Rimayi et al. 2018). En el caso de la ametrina se encontraron altas concentraciones en muestras de sedimentos, indicando su persistencia en ríos (Jacomini et al. 2011). La presencia de plaguicidas en el ambiente como consecuencia de su uso ha obligado a implementar medidas para regular su utilización. El uso de la atrazina está restringido en los Estados Unidos de América (EUA) y prohibido en algunos países europeos, mientras que su uso está permitido en México y en la mayoría de los países latinoamericanos. En el caso del agua para consumo humano, en EUA se tiene un límite de concentración de atrazina de $3 \mu \mathrm{g} / \mathrm{L}$ (USEPA 2003) y de $0.1 \mu \mathrm{g} / \mathrm{L}$ en la Comunidad Europea. En México, la NOM-127SSA-1994 (SSA 2000) que establece las concentraciones máximas permitidas para agua de consumo humano, considera algunos plaguicidas, pero no hay regulación para herbicidas triazínicos como lo son la atrazina y la ametrina.

Por todo lo antes mencionado, diversos grupos de investigación han dirigido su atención hacia la degradación de la atrazina. Sin embargo, la ametrina ha sido poco estudiada. La remoción de estos herbicidas recalcitrantes puede ser posible con el uso de consorcios microbianos especializados. Anteriormente se habían aislado bacterias que mostraban dificultad para crecer en herbicidas triazínicos como única fuente de carbono o nitrógeno. Recientemente, se han aislado algunas especies bacterianas que pueden crecer en estos herbicidas, removiéndolos eficientemente de los sistemas acuáticos, de aquí la idea de que nuevas rutas metabólicas para el catabolismo de los herbicidas triazínicos pudieran haberse diversificado evolutivamente (Shapir et al. 2007). Varios grupos de investigación ya han encontrado diversidad de microorganismos capaces de degradar atrazina (Mandelbaum et al. 1995, De Souza et al. 1998, Rousseaux et al. 2001, Tafoya-Garnica et al. 2009, Nissim et al. 2014). Sin embargo, son pocos los procesos que han propuesto su uso para la biorremediación de sitios contaminados con el herbicida ametrina, sólo, o formando parte de una mezcla con atrazina (Nishimura et al. 2002, Sandoval-Carrasco et al. 2013). En este trabajo, se evalúa la biodegradación de la mezcla comercial de ametrina más atrazina por una comunidad microbiana, utilizando diferentes tipos de cultivo.

\section{MATERIALES Y MÉTODOS}

\section{Herbicidas}

Los estándares de los herbicidas fueron adquiridos de Sigma-ALdrich Inc., Steinheim Germany: atrazina (98.8 \% de pureza), ametrina $(98.5 \%$ de pureza) y ácido cianúrico ( $98 \%$ de pureza). Para los experimentos de biodegradación de los herbicidas, se utilizó el herbicida comercial Gesapax ${ }^{\circledR}$ Combi $80 \mathrm{PH}$ comercializado en México cuya composición es: $38.2 \%$ de ametrina, $38.2 \%$ de atrazina y $23.6 \%$ de diluyentes, humectantes y dispersantes.

\section{Microorganismos}

La comunidad microbiana utilizada en este trabajo fue aislada utilizando el método de transferencias sucesivas en cultivos por lote. En matraces Erlenmeyer de $500 \mathrm{~mL}$ conteniendo $100 \mathrm{~mL}$ de medio mínimo mineral, adicionado con $97.61 \mathrm{mg} / \mathrm{L}$ de la mezcla comercial de los herbicidas, equivalente a $51.2 \mathrm{mg} / \mathrm{L}$ de ametrina y $46.4 \mathrm{mg} / \mathrm{L}$ de atrazina, se colocaron $10 \mathrm{~g}$ de suelo agrícola de Xochimilco, México. Los matraces se incubaron en una agitadora orbital con agitación constante a temperatura ambiente y se realizaron transferencias de alícuotas de $5 \mathrm{~mL}$ a matraces que contenían medio mínimo mineral con la misma concentración de la mezcla de los herbicidas. Lo anterior se repitió cada tres semanas, hasta observar que los valores de absorbancia correspondientes al máximo de absorción de cada herbicida al final del cultivo no se modificaron con respecto a la transferencia anterior $( \pm 5 \%)$.

Los microorganismos cultivables predominantes fueron identificados mediante la reacción en cadena de la polimerasa (PCR) y secuenciación, tal como se indica en el apartado de métodos analíticos, como pertenecientes a los géneros: Acinetobacter, Pseudomonas y Arthrobacter.

\section{Medio mínimo mineral}

El medio de cultivo utilizado fue el mismo en todas las etapas del trabajo. El medio mínimo mineral (MMM) fue preparado haciendo una modificación del descrito por Galíndez-Nájera et al. (2011) y contenía, en $\mathrm{g} / \mathrm{L}: \mathrm{K}_{2} \mathrm{HPO}_{4}, 0.4 ; \mathrm{KH}_{2} \mathrm{PO}_{4}$, $0.2 ; \mathrm{MgSO}_{4} .7 \mathrm{H}_{2} \mathrm{O}, 0.2 ; \mathrm{NaCl}, 0.1 ; \mathrm{CaCl}_{2}, 0.02$. El medio se complementó con los siguientes oligoelementos, obteniendo una concentración final (en $\mathrm{mg} / \mathrm{L}$ ) de $\mathrm{FeSO}_{4} \cdot 7 \mathrm{H}_{2} \mathrm{O}, 2.75 ; \mathrm{MnSO}_{4} \cdot 7 \mathrm{H}_{2} \mathrm{O}$, 
1.70; $\mathrm{ZnSO}_{4} \cdot 7 \mathrm{H}_{2} \mathrm{O}, 1.15 ; \mathrm{CoCl}_{2} \cdot 6 \mathrm{H}_{2} \mathrm{O}, 0.325$; $\mathrm{Na}_{2} \mathrm{MoO}_{4} \cdot 2 \mathrm{H}_{2} \mathrm{O}, 0.17$. Para evaluar si los ingredientes activos del producto comercial podrían ser usados como fuente de nitrógeno, se calculó la relación carbono-nitrógeno $(\mathrm{C} / \mathrm{N})$ de las moléculas de atrazina y ametrina en conjunto, obteniéndose una relación con un valor de 1.45 , considerándose una relación balanceada (Galíndez-Nájera et al. 2009), por lo que al MMM utilizado durante el aislamiento y en los procesos de degradación, se le adicionó como única fuente de carbono y nitrógeno, el herbicida comercial con la mezcla de atrazina y ametrina, Gesapax ${ }^{\circledR}$ Combi $80 \mathrm{PH}$, hasta alcanzar una concentración final de $97.61 \mathrm{mg} / \mathrm{L}$, medida por cromatografía de líquidos de alta resolución (HPLC).

\section{Biorreactor para los cultivos con células en sus- pensión}

El reactor utilizado fue un matraz Erlenmeyer de un litro de capacidad, modificado con dos vástagos, uno para toma de muestra y otro para salida del medio. El matraz se colocó sobre un agitador magnético para mantener el cultivo en agitación constante, por la parte superior se colocó el ducto para la aireación y el ducto de alimentación, el volumen de operación fue de $600 \mathrm{~mL}$ (Fig. 1).

\section{Biorreactor para los cultivos con células inmovi- lizadas (biobarrera)}

Se empleó un reactor de lecho empacado horizontal construido en material de acrílico de las siguientes dimensiones: $18 \mathrm{~cm}$ de alto, $15 \mathrm{~cm}$ de largo, $12 \mathrm{~cm}$ de ancho, $3240 \mathrm{~mL}$ de volumen total y $2937.6 \mathrm{~mL}$ de volumen de operación. La biobarrera contaba con tres secciones separadas por placas del mismo material comunicadas por aperturas longitudinales. En tres de las secciones se llevaba a cabo la aireación y los cuatro compartimentos contenían fragmentos de roca volcánica (Fig.1).

\section{Material de soporte}

Se utilizaron fragmentos de piedra volcánica (llamada tezontle en México) como soporte poroso en el reactor de biopelícula. Estos fragmentos se consideraron como cuerpos elipsoidales con tres radios característicos: a, b, c. El volumen de partícula se calculó determinando el diámetro equivalente $\left(\mathrm{d}_{\mathrm{p}}\right)$ de los fragmentos de piedra volcánica (Galíndez-Nájera et al. 2009). El valor promedio $d_{p}$ fue de $7.61 \mathrm{~mm}$. El volumen de soporte utilizado en la biobarrera fue de $1442.6 \mathrm{~mL}$, con lo cual se obtuvo un volumen drenado de $1495 \mathrm{~mL}$.

\section{Operación del biorreactor con células en suspen- sión}

La comunidad microbiana seleccionada se propagó en matraces de $250 \mathrm{~mL}$ con $50 \mathrm{~mL}$ de MMM esterilizado, adicionado con $97.61 \mathrm{mg} / \mathrm{L}$ de la mezcla comercial de los herbicidas atrazina y ametrina, los matraces se mantuvieron a temperatura ambiente y en agitación a $60 \mathrm{rpm}$ por $72 \mathrm{~h}$. Se recuperó la biomasa producida y se resuspendió en $2 \mathrm{~mL}$ del mismo
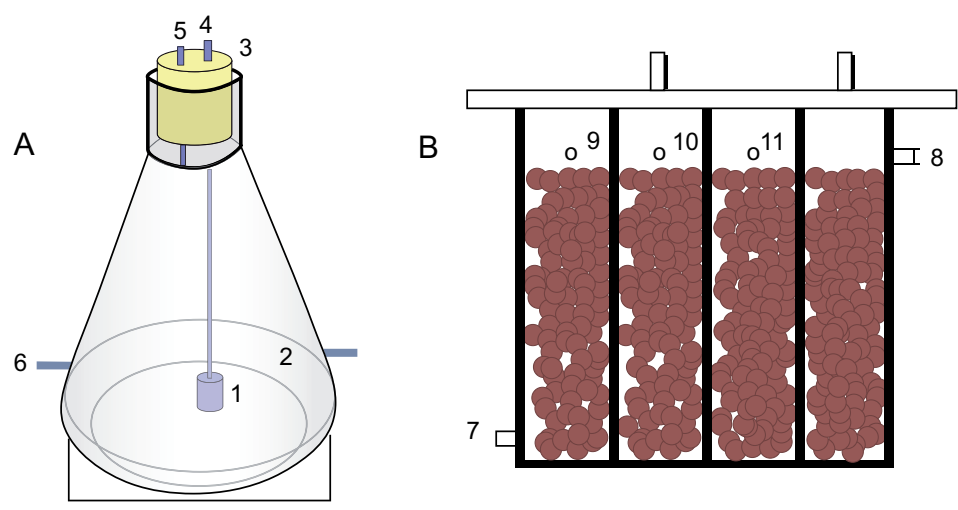

Fig. 1. Biorreactores. A. Biorreactor para los cultivos con células en suspensión. 1. Ducto de aireación con difusor de piedra porosa. 2. Salida del medio durante la operación en continuo. 3. Tapón de hule. 4. Entrada de aire. 5. Entrada del flujo de alimentación. 6. Toma de muestra. B. Biorreactor para los cultivos con células inmovilizadas (biobarrera). 7. Entrada del flujo de alimentación. 8. Toma de muestra y salida del medio durante la operación en continuo. 9, 10, 11. Entrada de aire. 
medio, este volumen se adicionó como inóculo al reactor con $600 \mathrm{~mL}$ de MMM esterilizado, que contenía $97.61 \mathrm{mg} / \mathrm{L}$ de la mezcla comercial de los herbicidas. La concentración inicial de biomasa, cuantificada por cuenta viable fue de $2.9 \times 10^{6} \mathrm{UFC} / \mathrm{mL}$. El flujo de aireación permaneció constante a $0.3 \mathrm{~L} / \mathrm{min}$. Se registró periódicamente la concentración celular y la concentración residual de los herbicidas hasta obtener una buena eficiencia de remoción (medida espectrofotométricamente). Posteriormente se drenó el $92 \%$ del volumen de medio y se completó con el mismo volumen de medio nuevo esterilizado para iniciar con un nuevo cultivo por lote. La implementación de este sistema de cultivo, llamado por lotes repetidos o por lote semicontinuo, es una estrategia para favorecer la formación de biomasa y por lo tanto prolongar la operación de los reactores y en consecuencia reducir los costos de operación (Victores et al. 2008, Desai 2015). Una vez que se terminó con el cultivo por lote semicontinuo se inició la alimentación continua del biorreactor con MMM adicionado con la mezcla comercial de los herbicidas que contenía $51.2 \mathrm{mg} / \mathrm{L}$ de ametrina y $46.4 \mathrm{mg} / \mathrm{L}$ de atrazina, el medio fue previamente esterilizado. Los flujos de alimentación probados variaron desde 20 hasta $180 \mathrm{~mL} / \mathrm{h}$, correspondiendo a diferentes tiempos de retención hidráulica (TRH), que variaron desde 30 hasta $3.3 \mathrm{~h}$ respectivamente y diferentes cargas de alimentación (Bv) (Cuadro II). Las muestras del efluente se analizaron periódicamente para determinar la demanda química de oxígeno (DQO), concentración de ametrina, atrazina y ácido cianúrico.

\section{Operación de la biobarrera}

Previamente a la operación de la biobarrera, el soporte utilizado fue esterilizado en un horno Fisher Scientific modelo $718 \mathrm{~F}$, a $160^{\circ} \mathrm{C}$ por un tiempo de 2 $\mathrm{h}$ para posteriormente introducirlo en el reactor de biopelícula. Para saturar el soporte con los herbicidas, inicialmente se operó la biobarrera en condiciones abióticas mediante la alimentación continua de MMM conteniendo la mezcla de los herbicidas, previamente esterilizado. La concentración de herbicidas en el efluente de la biobarrera se determinó diariamente. Una vez que las concentraciones de los herbicidas fueron iguales en el efluente que en el influente, se determinó que el soporte estaba saturado y por lo tanto cualquier cambio de concentración en el efluente se debería exclusivamente a la actividad de la comunidad microbiana inoculada posteriormente. Después de la saturación, la biobarrera se drenó parcialmente y se inoculó con la comunidad microbiana previamente crecida en medio mínimo mineral con la mezcla de los herbicidas. El flujo de aireación permaneció constante a $0.3 \mathrm{~L} / \mathrm{min}$. Para facilitar la colonización del soporte se mantuvo en cultivo por lote durante siete días. Posteriormente se drenó totalmente el biorreactor y se completó nuevamente con medio nuevo para iniciar un nuevo ciclo. Después de realizar 10 cultivos por lote repetidos, también llamados ciclos de un cultivo por lote semicontinuo, se alimentó continuamente la biobarrera con medio mínimo mineral que contenía la mezcla de los herbicida, previamente esterilizada. Los flujos de alimentación probados variaron desde 15 hasta $360 \mathrm{~mL} / \mathrm{h}$, correspondiendo a diferentes $\mathrm{TRH}$, que variaron desde $99.67 \mathrm{~h}$ hasta $4.15 \mathrm{~h}$. Se tomaron muestras del efluente analizando la DQO y las concentraciones de ametrina, atrazina y ácido cianúrico.

\section{Métodos analíticos \\ Determinación de ametrina, atrazina y ácido cia- núrico}

A partir de las muestras centrifugadas se determinó la concentración de los herbicidas. Para una rápida evaluación de los cambios en las concentraciones de los herbicidas, se midió la absorbancia de cada una de las muestras a $223 \mathrm{~nm}$, que es la longitud de onda a la cual se presentó la máxima absorción del herbicida comercial en un espectrofotómetro Beckman DU®650. Posteriormente la concentración de ametrina, atrazina y ácido cianúrico se determinó mediante HPLC utilizando un sistema de HPLC Beckman, modelo System Gold, equipado con una columna Nova Pack C18 y un detector 168 UV a $\Lambda=221 \mathrm{~nm}$. La separación cromatográfica se realizó usando un gradiente lineal de un regulador de fosfatos $10 \mathrm{mM}(\mathrm{pH}=7)$ con acetonitrilo, incrementando de $30 \%$ a $70 \%$ en 12 min.

\section{Concentración de células suspendidas o inmovi- lizadas}

Durante la operación de cada uno de los biorreactores, ya sea con células suspendidas o inmovilizadas, se determinó la concentración celular por cuenta viable en unidades formadoras de colonias (UFC/mL). Una vez que terminaron las corridas del cultivo continuo con células inmovilizadas, se tomaron muestras de fragmentos de roca volcánica utilizada como soporte para determinar la biomasa adsorbida (UFC/ [g soporte poroso seco]). Las células fueron extraídas del soporte con agua con la ayuda de un agitador vórtex y se hicieron diluciones apropiadas para el conteo en placa. 


\section{Demanda química de oxígeno (DQO)}

Se utilizó el método 8000 de Hach, las muestras líquidas se centrifugaron y se hicieron las diluciones apropiadas para su análisis (Hach 2012).

\section{Identificación de los microorganismos}

Se realizaron diluciones seriadas y sembrado en placas a partir de las cuales se aislaron las bacterias que mostraron diferencias en su morfología colonial. Para extraer el ADN, cada uno de los aislados se propagó en medio Luria Bertani ( $1 \%$ de triptona, $0.5 \%$ de extracto de levadura, $1.0 \%$ de $\mathrm{NaCl} ; \mathrm{pH}$ 7.0). Posteriormente, se identificaron amplificando mediante PCR una región variable del $16 \mathrm{~S} \mathrm{ADNr}$, comprendido entre las regiones altamente conservadas en organismos procariotes, utilizando los iniciadores U968-GC y L1401 (Felske et al. 1996). Los amplicones obtenidos se purificaron empleando el kit Purelink de Invitrogen y la secuenciación de los amplificados de ADN fue realizada por la compañía Macrogen Inc en Seúl, Corea. Las secuencias obtenidas de cada uno de los aislados se compararon con secuencias de bases depositadas en el banco de genes del Centro Nacional para la Información Biotecnológica (NCBI) empleando el programa informático de alineamiento de secuencias (BLAST), para definir la similitud con el microorganismo más cercano.

\section{RESULTADOS}

\section{Biodegradación de la mezcla de los herbicidas en cultivo por lote semicontinuo con células en suspensión}

Después de la inoculación del reactor con la comunidad previamente seleccionada por su capacidad para degradar herbicidas triazínicos, conformada por microorganismos pertenecientes a los géneros Acinetobacter, Pseudomonas y Arthrobacter, se inició el cultivo por lote semicontinuo. En cada ciclo, se determinó periódicamente la concentración de ametrina y atrazina. Para una evaluación rápida, la determinación se hizo por espectrofotometría a una $\Lambda=223 \mathrm{~nm}$. Cada ciclo del cultivo por lote semicontinuo finalizó cuando el valor de la absorbancia permaneció constante. Al final de cada ciclo se tomaron muestras del efluente y se centrifugaron para determinar la concentración de ametrina, atrazina y ácido cianúrico por HPLC y la DQO. Se realizaron 23 ciclos del cultivo por lote semicontinuo. En todos los ciclos se obtuvo una eficiencia de remoción del $100 \%$ para ambos herbicidas y velocidades volumé- tricas de remoción de hasta $5.44 \pm 1.68 \mathrm{mg} / \mathrm{L} / \mathrm{h}$. La eficiencia de remoción de la DQO fluctuó entre 85.41 $\pm 5.58 \%$ (Cuadro I). Con los datos obtenidos en el cultivo por lote semicontinuo se determinó la vida media de la ametrina y de la atrazina, considerando el modelo de desintegración de primer orden (Webb et al. 2011). Para los primeros ocho ciclos se obtuvo una vida media de $2.43 \pm 0.01 \mathrm{~h}$ para la atrazina y de $2.23 \pm 0.03 \mathrm{~h}$ para la ametrina, para los ciclos nueve al quince la vida media fue de $1.38 \pm 0.01 \mathrm{~h}$ para la atrazina y de $1.31 \pm 0.01 \mathrm{~h}$ para la ametrina, en los últimos ocho ciclos la vida media fue de tan sólo $1.08 \pm 0.01 \mathrm{~h}$ para la atrazina y de $1 \pm 0.02 \mathrm{~h}$ para la ametrina (Cuadro I).

\section{Biodegradación de la mezcla de los herbicidas en cultivo continuo con células en suspensión}

Una vez concluido el cultivo por lote semicontinuo se inició el cultivo continuo, la concentración de biomasa inicial fue de $18 \times 10^{6} \mathrm{UFC} / \mathrm{mL}$, llegando a una concentración de $54 \times 10^{6} \mathrm{UFC} / \mathrm{mL}$ en el último flujo de alimentación probado. Se evaluaron seis diferentes flujos de alimentación, de 20 a $180 \mathrm{~mL} / \mathrm{h}$ que corresponden a los TRH de 30 a $3.3 \mathrm{~h}$. El flujo de aireación permaneció constante a $0.3 \mathrm{~L} / \mathrm{min}$. En el caso de la ametrina las eficiencias de remoción alcanzaron el $100 \%$ a todos los flujos de alimentación probados, no así para el caso de la atrazina, en donde la eficiencia de remoción fluctuó entre el $93.41 \pm 2.15 \%$ y el $95.79 \pm 3.58 \%$. La eficiencia de remoción de la DQO, varió del $82.13 \pm 0.01$ al 89.29 $\pm 02 \%$ (Cuadro II).

En la figura 2 se muestra la velocidad volumétrica de remoción de la ametrina $\left(\mathrm{Rv}_{\mathrm{AMT}}\right)$ y de la atrazina (RVATz) obtenidas a diferentes cargas de alimentación de la mezcla comercial de los herbicidas (BVATZ,AMT); así como la velocidad volumétrica de remoción de la DQO (RV,DQO) en función de la carga suministrada. Para poder apreciar la capacidad de la comunidad microbiana para consumir el ácido cianúrico formado se graficó la velocidad de formación del ácido cianúrico experimental y la velocidad de formación teórica (esperada de acuerdo con la estequiometría de la reacción) en función de la carga volumétrica de los herbicidas

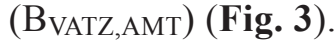

En el transcurso del cultivo continuo se fue formando una biopelícula adherida a las paredes del reactor que se fue incrementando a lo largo del tiempo (Fig. 4). La formación de esta biopelícula nos dio la pauta para la utilización de un reactor de lecho empacado en la biodegradación de la mezcla comercial de los herbicidas. 
BIODEGRADACIÓN DE ATRAZINA Y AMETRINA

CUADRO I. VELOCIDADES VOLUMÉTRICAS, EFICIENCIAS DE REMOCIÓN Y VIDA MEDIA DE AMETRINA Y ATRAZINA. VELOCIDAD Y EFICIENCIA DE REMOCIÓN DE LA DEMANDA QUÍMICA DE OXÍGENO, EN EL CULTIVO POR LOTE SEMICONTINUO EN EL QUIMIOSTATO Y EN LA BIOBARRERA

\begin{tabular}{|c|c|c|c|c|c|}
\hline \multicolumn{6}{|c|}{ Cultivo por lote semicontinuo } \\
\hline & \multicolumn{3}{|c|}{ Quimiostato } & \multicolumn{2}{|c|}{ Biobarrera } \\
\hline & Ciclo 1-8 & Ciclo 9-15 & Ciclo $16-23$ & Ciclo 1-5 & Ciclo 6-10 \\
\hline $\operatorname{Rv}_{\text {ATZ }}(\mathrm{mg} / \mathrm{L} / \mathrm{h})$ & $2.40 \pm 0.57$ & $4.83 \pm 2.65$ & $4.93 \pm 1.55$ & $2.96 \pm 1.98$ & $5.47 \pm 2.12$ \\
\hline$\eta_{\text {ATZ }}(\%)$ & $99.50 \pm 0.40$ & $99.50 \pm 0.45$ & $99.5 \pm 0.50$ & $99.75 \pm 0.20$ & $99.80 \pm 0.20$ \\
\hline$t_{1} / 2 \operatorname{ATZ}(h)$ & $2.43 \pm 0.01$ & $1.38 \pm 0.01$ & $1.08 \pm 0.01$ & $2.86 \pm 0.12$ & $1.00 \pm 0.02$ \\
\hline $\mathrm{Rv}_{\text {AMT }}(\mathrm{mg} / \mathrm{L} / \mathrm{h})$ & $2.65 \pm 0.62$ & $5.33 \pm 2.95$ & $5.44 \pm 1.68$ & $3.46 \pm 2.42$ & $6.05 \pm 2.35$ \\
\hline$\eta_{\text {AMT }}(\%)$ & $99.70 \pm 0.25$ & $99.82 \pm 0.15$ & $99.90 \pm 0.01$ & $99.92 \pm 0.02$ & $99.94 \pm 0.01$ \\
\hline $\mathrm{t}_{1 / 2} \mathrm{AMT}(\mathrm{h})$ & $2.23 \pm 0.03$ & $1.31 \pm 0.01$ & $1.00 \pm 0.02$ & $1.89 \pm 0.15$ & $0.96 \pm 0.05$ \\
\hline $\operatorname{RV}_{D Q O}(\mathrm{mg} / \mathrm{L} / \mathrm{h})$ & $3.20 \pm 0.83$ & $4.90 \pm 1.80$ & $13.36 \pm 2.01$ & $5.87 \pm 4.10$ & $10.24 \pm 3.97$ \\
\hline$\eta_{\mathrm{DQO}}(\%)$ & $85.41 \pm 5.58$ & $87.50 \pm 1.01$ & $85.71 \pm 2.51$ & $99.95 \pm 0.02$ & $99.97 \pm 0.02$ \\
\hline
\end{tabular}

Velocidad volumétrica de remoción de atrazina $\left(\operatorname{Rv}_{\mathrm{ATZ}}\right)$, eficiencia de remoción de atrazina $\left(\eta_{\mathrm{ATZ}}\right)$, vida media de atrazina $\left(t_{1} / 2 A T Z\right)$, velocidad volumétrica de remoción de ametrina $\left(\mathrm{Rv}_{\mathrm{AMT}}\right)$, eficiencia de remoción de ametrina $\left(\eta_{\mathrm{AMT}}\right)$, vida media de ametrina ( $\mathrm{t} 1 \frac{2 \mathrm{AMT}}{\mathrm{A}}$ ), velocidad volumétrica de remoción de la demanda química de oxígeno (RVDQO), eficiencia de remoción de la demanda química de oxígeno ( $\left.\eta_{\mathrm{DQO}}\right)$. Concentraciones medidas por cromatografía de líquidos de alta resolución

CUADRO II. VELOCIDADES VOLUMÉTRICAS, EFICIENCIAS DE REMOCIÓN DE AMETRINA Y ATRAZINA. VELOCIDAD Y EFICIENCIA DE REMOCIÓN DE LA DEMANDA QUÍMICA DE OXÍGENO, OBTENIDOS DURANTE EL CULTIVO CONTINUO EN EL QUIMIOSTATO Y EN LA BIOBARRERA

\begin{tabular}{|c|c|c|c|c|c|c|}
\hline \multicolumn{7}{|c|}{ Cultivo continuo } \\
\hline \multicolumn{7}{|c|}{ Quimiostato } \\
\hline Flujo (mL/h) & 20 & 40 & 54 & 84 & 115 & 180 \\
\hline HRT (h) & 30 & 15 & 11.11 & 7.14 & 5.21 & 3.33 \\
\hline $\mathrm{Bv}_{\mathrm{ATZ}}(\mathrm{mg} / \mathrm{L} / \mathrm{h})$ & $1.54 \pm 0.55$ & $3.09 \pm 0.20$ & $4.17 \pm 0.20$ & $6.49 \pm 0.20$ & $8.89 \pm 0.20$ & $13.91 \pm 0.05$ \\
\hline $\mathrm{Rv}_{\mathrm{ATZ}}(\mathrm{mg} / \mathrm{L} / \mathrm{h})$ & $1.51 \pm 0.02$ & $2.99 \pm 0.05$ & $4.17 \pm 0.20$ & $6.06 \pm 0.20$ & $8.42 \pm 0.20$ & $13.91 \pm 0.02$ \\
\hline $\mathrm{Bv}_{\text {AMT }}(\mathrm{mg} / \mathrm{L} / \mathrm{h})$ & $1.71 \pm 0.14$ & $3.41 \pm 0.42$ & $4.61 \pm 0.25$ & $7.17 \pm 0.25$ & $9.81 \pm 0.25$ & $15.36 \pm 0.54$ \\
\hline $\operatorname{Rv}_{\text {AMT }}(\mathrm{mg} / \mathrm{L} / \mathrm{h})$ & $1.70 \pm 0.05$ & $3.41 \pm 0.40$ & $4.61 \pm 0.21$ & $7.17 \pm 0.21$ & $9.81 \pm 0.21$ & $15.36 \pm 0.45$ \\
\hline$\prod_{\mathrm{ATZ}}(\%)$ & $96.86 \pm 1.15$ & $93.41 \pm 2.15$ & $95.79 \pm 3.58$ & $95.79 \pm 3.58$ & $95.79 \pm 3.58$ & $96.86 \pm 1.15$ \\
\hline$\prod_{\mathrm{AMT}}(\%)$ & $99.52 \pm 0.48$ & $99.67 \pm 0.33$ & $99.81 \pm 0.19$ & $99.81 \pm 0.19$ & $99.81 \pm 0.19$ & $99.52 \pm 0.48$ \\
\hline $\mathrm{BV}_{\mathrm{DQO}}(\mathrm{mg} / \mathrm{L} / \mathrm{h})$ & $5.97 \pm 0.03$ & $12.54 \pm 0.01$ & $17.17 \pm 0.02$ & $17.17 \pm 0.02$ & $17.17 \pm 0.02$ & $5.97 \pm 0.03$ \\
\hline RvDQO (mg/L/h) & $5.33 \pm 0.20$ & $10.30 \pm 0.52$ & $15.33 \pm 0.27$ & $15.33 \pm 0.27$ & $15.33 \pm 0.27$ & $5.33 \pm 0.20$ \\
\hline$\eta_{\mathrm{DQO}}(\%)$ & $89.29 \pm 0.02$ & $82.13 \pm 0.01$ & $89.28 \pm 0.01$ & $89.28 \pm 0.01$ & $89.28 \pm 0.01$ & $89.29 \pm 0.02$ \\
\hline \multicolumn{7}{|c|}{ Biobarrera } \\
\hline Flujo (mL/h) & 15 & 30 & 60 & 126 & 250 & 360 \\
\hline HRT (h) & 99.67 & 49.83 & 24.92 & 11.87 & 5.98 & 4.15 \\
\hline $\mathrm{Bv}_{\text {ATZ,AMT }}(\mathrm{mg} / \mathrm{L} / \mathrm{h})$ & $0.49 \pm 0.02$ & $0.99 \pm 0.03$ & $1.99 \pm 0.02$ & $4.18 \pm 0.03$ & $8.3 \pm 0.02$ & $11.96 \pm 0.03$ \\
\hline $\mathrm{Rv}_{\mathrm{ATZ}, \mathrm{AMT}}(\mathrm{mg} / \mathrm{L} / \mathrm{h})$ & $0.49 \pm 0.01$ & $0.99 \pm 0.02$ & $1.99 \pm 0.01$ & $4.18 \pm 0.02$ & $8.3 \pm 0.02$ & $11.96 \pm 0.03$ \\
\hline$\prod_{\text {ATZ,AMT }}(\%)$ & $99.98 \pm 0.01$ & $99.82 \pm 0.18$ & $99.95 \pm 0.05$ & $99.97 \pm 0.03$ & $99.85 \pm 0.15$ & $99.9 \pm 0.10$ \\
\hline $\mathrm{BV}_{\mathrm{DQO}}(\mathrm{mg} / \mathrm{L} / \mathrm{h})$ & $0.41 \pm 0.12$ & $0.80 \pm 0.09$ & $1.60 \pm 0.15$ & $3.37 \pm 0.11$ & $6.69 \pm 0.21$ & $9.63 \pm 0.17$ \\
\hline $\operatorname{RV}_{D Q O}(\mathrm{mg} / \mathrm{L} / \mathrm{h})$ & $0.41 \pm 0.11$ & $0.80 \pm 0.05$ & $1.60 \pm 0.10$ & $3.37 \pm 0.09$ & $6.69 \pm 0.18$ & $9.63 \pm 0.02$ \\
\hline$\eta_{\mathrm{DQO}}(\%)$ & $99.99 \pm 0.01$ & $99.96 \pm 0.05$ & $99.95 \pm 0.05$ & $99.98 \pm 0.02$ & $99.97 \pm 0.03$ & $99.85 \pm 0.15$ \\
\hline
\end{tabular}

Tiempo de residencia hidráulico (HRT), carga volumétrica de atrazina $\left(\mathrm{Bv}_{\mathrm{ATZ}}\right)$, velocidad volumétrica de remoción de atrazina $\left(\mathrm{Rv}_{\mathrm{ATZ}}\right)$, carga volumétrica de ametrina $\left(\mathrm{Bv}_{\mathrm{AMT}}\right)$, velocidad volumétrica de remoción de ametrina $\left(\mathrm{Rv}_{\mathrm{AMT}}\right)$, eficiencia de remoción de atrazina $\left(\prod_{\mathrm{ATZ}}\right)$, eficiencia de remoción de ametrina $\left(\prod_{\mathrm{AMT}}\right)$, carga volumétrica de la demanda química de oxígeno (BVDQO), velocidad volumétrica de la demanda química de oxígeno (RVDQO), eficiencia de remoción de la demanda química de oxígeno ( $\mathrm{DQQO}_{\mathrm{DQ}}$ ). Concentraciones medidas por cromatografía de líquidos de alta resolución. 

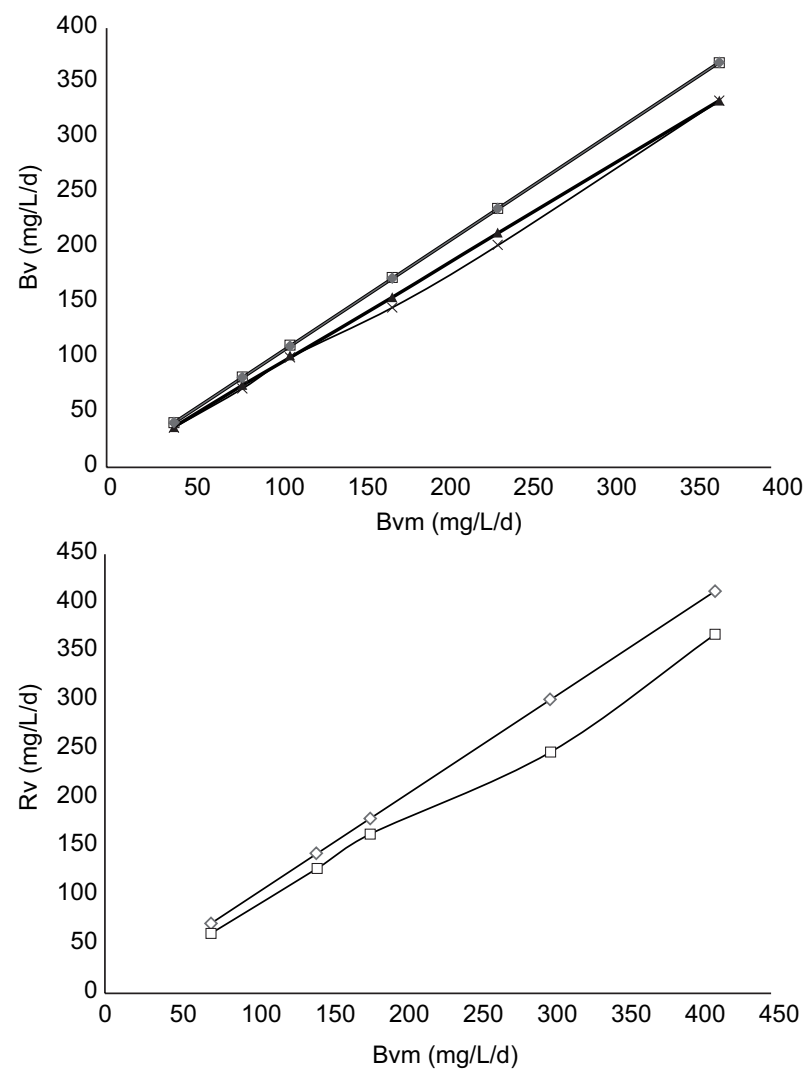

Fig. 2. Velocidad volumétrica de remoción de los herbicidas $(\mathrm{Rv})$ ametrina y atrazina en función de la carga volumétrica (Bvm), dada por los diferentes flujos de alimentación con células en suspensión en cultivo continuo. a) Cuantificación por cromatografía de líquidos de alta resolución (HPLC), ( $\square)$ Rv teórica de ametrina, $(\diamond) \mathrm{Rv}$ de ametrina, $(\Delta)$ Rv teórica de atrazina, $(\times)$ Rv de atrazina; b) Cuantificación por demanda química de oxígeno (DQO), $(\diamond)$ Rv teórica, ( $\square)$ Rv experimental

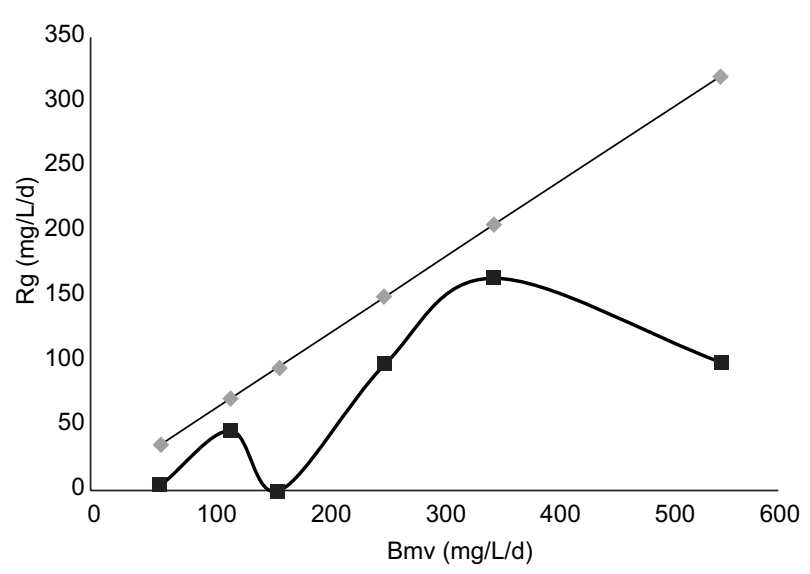

Fig. 3. Velocidad de formación $(\mathrm{Rg})$ teórica $(\downarrow)$ y experimental (匹)de ácido cianúrico durante el cultivo continuo con células libres (planctónicas) en función de la carga volumétrica (Bvm) de los herbicidas. La velocidad de acumulación teórica se refiere al ácido cianúrico estequiométricamente formado
Biodegradación de la mezcla de los herbicidas con células inmovilizadas en cultivo por lote semicontinuo utilizando un reactor de lecho empacado (biobarrera)

Se realizaron un total de 10 ciclos del cultivo por lote semicontinuo. La velocidad volumétrica de degradación de los herbicidas fue aumentando de $2.96 \pm 1.98 \mathrm{mg} / \mathrm{L} / \mathrm{h}$ en los primeros ciclos hasta $5.47 \pm 2.12 \mathrm{mg} / \mathrm{L} / \mathrm{h}$ en los últimos ciclos para la atrazina. En el caso de la ametrina el aumento fue de $3.46 \pm 2.42$ en los primeros ciclos a $6.05 \pm 2.35$ $\mathrm{mg} / \mathrm{L} / \mathrm{h}$ en los últimos (Cuadro I). La eficiencia de remoción fue del $100 \%$ para ambos herbicidas. En este sistema se obtuvieron eficiencias de remoción de la DQO del $100 \%$ para todos los ciclos. La degradación del ácido cianúrico fue analizada por HPLC. En la figura 5 se muestra la concentración de ácido cianúrico que se alcanzaría teóricamente, por estequiometría de la degradación de los herbicidas, si no fuera consumido, así como la concentración experimental del ácido cianúrico obtenida en los diferentes ciclos. Como resultado se puede notar la elevada remoción del compuesto en los últimos ciclos secuenciales, que probablemente responda a una aclimatación de la comunidad y a una mayor colonización del soporte.

Biodegradación de la mezcla de los herbicidas con células inmovilizadas en cultivo continuo utilizando un reactor de lecho empacado (biobarrera)

Una vez concluido el cultivo por lote semicontinuo, se operó el reactor de biopelícula en forma continua a diferentes flujos de alimentación, desde 15 hasta $360 \mathrm{~mL} / \mathrm{h}$, que corresponden a diferentes TRH probados, desde 99.67 hasta $4.15 \mathrm{~h}$ (Cuadro II). La figura 6 muestra la velocidad volumétrica de degradación de la mezcla ametrina-atrazina $\left(R v_{\text {ATZ,AMT }}\right)$, obtenida a diferentes cargas volumétricas (BvATZ,AMT), medida por HPLC y la velocidad volumétrica de degradación de la DQO (RvDQO). La cuantificación de los herbicidas por HPLC indicó que hubo completa degradación de la ametrina y la atrazina a todas las velocidades de dilución probadas; de igual manera que en el cultivo por lote semicontinuo, se observó completa degradación de la DQO (Cuadro II), lo que representa una gran ventaja del sistema sobre otros similares reportados para la biodegradación de herbicidas comerciales en mezclas con triazínicos (Sánchez-Sánchez et al. 2013, Sandoval-Carrasco et al. 2013).

Al analizar los cromatogramas obtenidos por HPLC, se detectó, al igual que en los cultivos anteriores, la presencia del pico que corresponde al ácido 

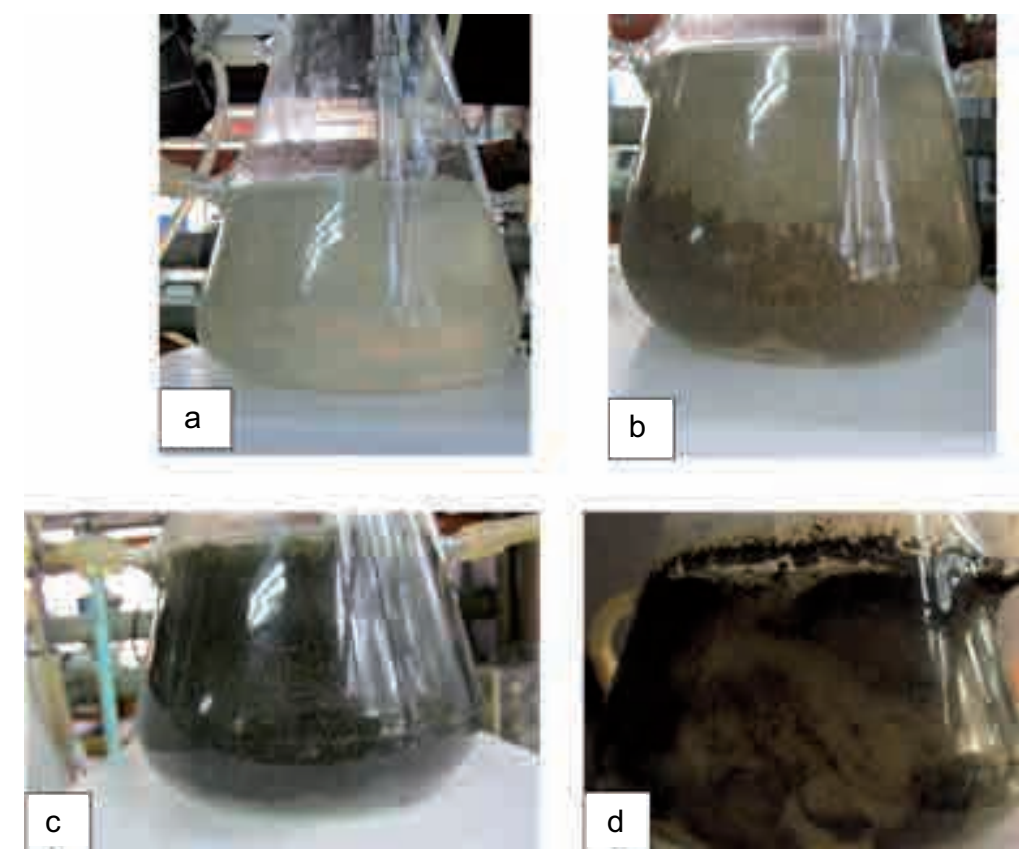

Fig. 4. Imágenes de la formación de la biopelícula: a) y b) Inicio de la formación de la biopelícula; c) biopelícula madura y d) desprendimiento de la biopelícula de las paredes del matraz

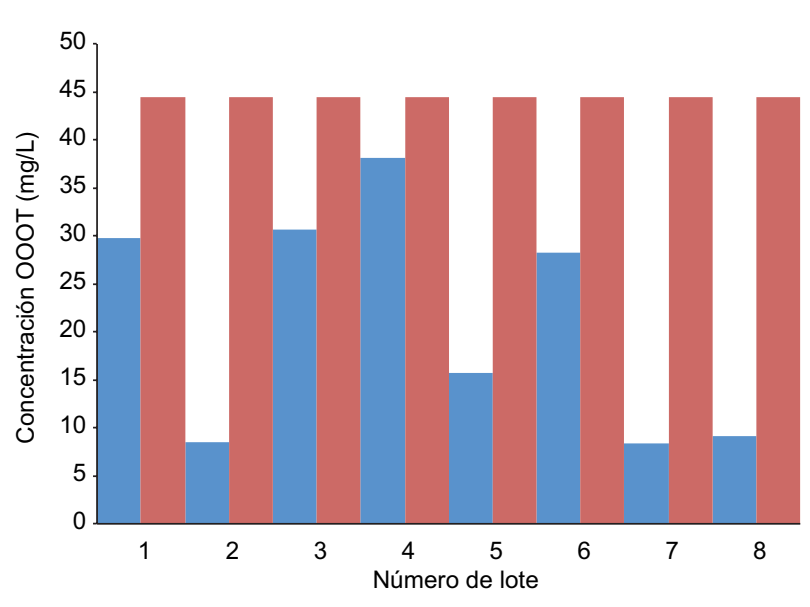

Fig. 5. Concentración teórica ( $\square$ ) y experimental ( $\square$ ) de ácido cianúrico (OOOT) en cada uno de los ciclos del cultivo por lote semicontinuo realizado en la biobarrera

cianúrico. Al analizar la remoción del ácido cianúrico formado en las primeras cargas de alimentación de los herbicidas se aprecian eficiencias de remoción considerables, del 86 al $87 \%$, porcentajes mayores a los reportados en otros trabajos sobre la degradación de herbicidas s-triazínicos (Sánchez-Sánchez et al. 2013). Cuando se incrementó la velocidad de dilución disminuyó sensiblemente la eficiencia de remoción de ácido cianúrico (Fig. 6).

\section{Aislamiento e identificación de los microorganis- mos cultivables predominantes en la comunidad microbiana}

Para determinar la permanencia de los integrantes de la comunidad, previamente aislada e identificada, a lo largo de los cultivos con células en suspensión y en la biobarrera, se realizó el aislamiento por morfología colonial y la identificación de los aislados tal como se indica en la sección de Materiales y Métodos. Al final del cultivo por lote semicontinuo y del proceso continuo se tomaron muestras de la fase líquida de los reactores de las cuales se aislaron e identificaron los microorganismos cultivables predominantes. Los microorganismos identificados fueron: Chryseobacterium daecheongenses (JF700424.1), Acinetobacter johnsonni (FJ976603.1), Microbacterium testaceum (KC764967.1), Pseudomonas aeruginosa (HM137028.2), Pseudomonas nitroreducens (KC355311.1), con un $99 \%$ de similitud en todos los casos. Comparando los géneros de microorganismos se observó que los integrantes de la comunidad microbiana que permanecieron como cepas importantes, fueron las correspondientes a los géneros Pseudomonas y Acinetobacter.

De la biobarrera se tomaron muestras del soporte, se desadsorbieron las células y se realizaron las diluciones adecuadas para el sembrado en placas, a partir de las cuales se aislaron los microorganismos 

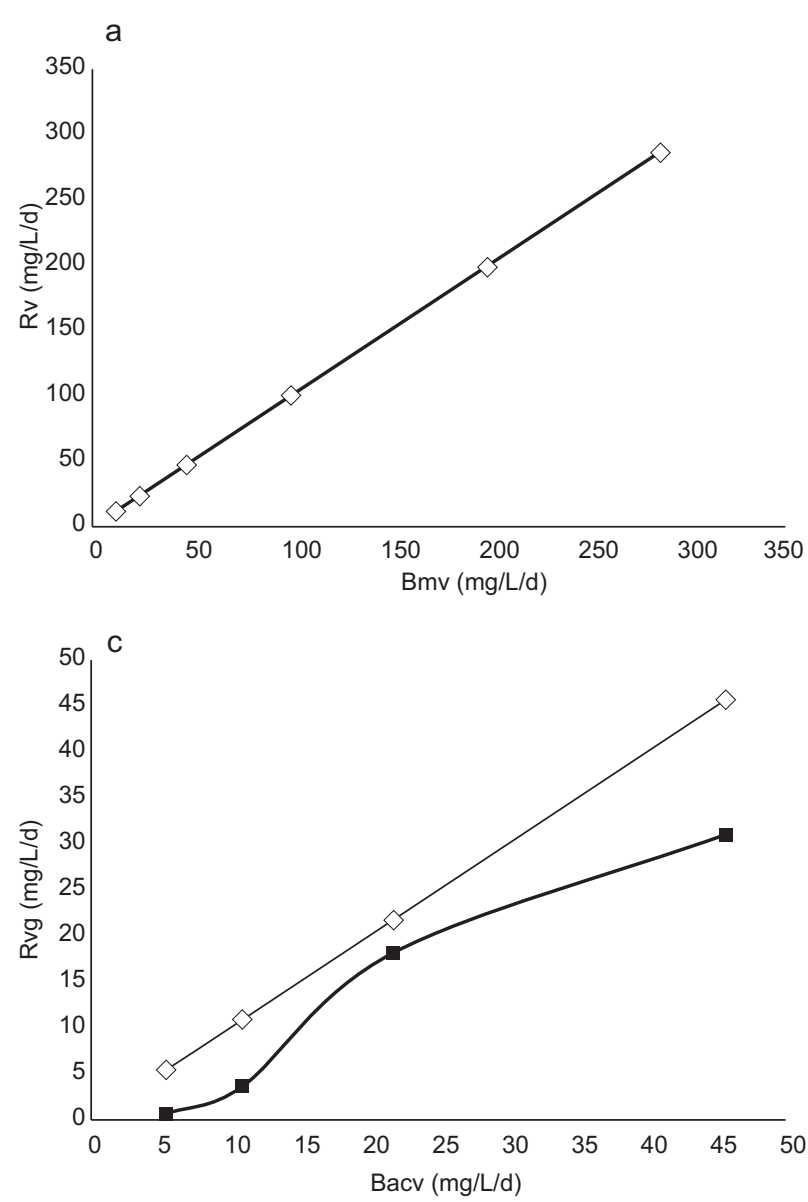

por diferencias en su morfología colonial. Después de la extracción de ADN, amplificación por PCR y secuenciación se pudieron identificar los microorganismos cultivables predominantes que se encontraban inmovilizados en la biobarrera (Cuadro III).

\section{Detección de los genes que codifican a enzimas que degradan compuestos triazínicos}

A partir de los aislados obtenidos de la biobarrera se amplificaron los genes que codifican a las enzimas involucradas en la ruta de degradación de compuestos s-triazínicos. Todos los genes en la comunidad se pudieron detectar por PCR (Cuadro III). En aquellos aislados en los que no fue posible detectar el primer gen en la vía de degradación de los s-triazínicos (gen $a t z A$ ), sí se encontró el gen $\operatorname{trz} N$, el cual tiene la misma función, pero con una menor especificidad (Harada 2007), lo que explica su presencia en prácticamente todos los aislados. El segundo gen en la vía, el gen $a t z B$ está presente en todos los aislados. El gen $a t z C$, que cataliza la

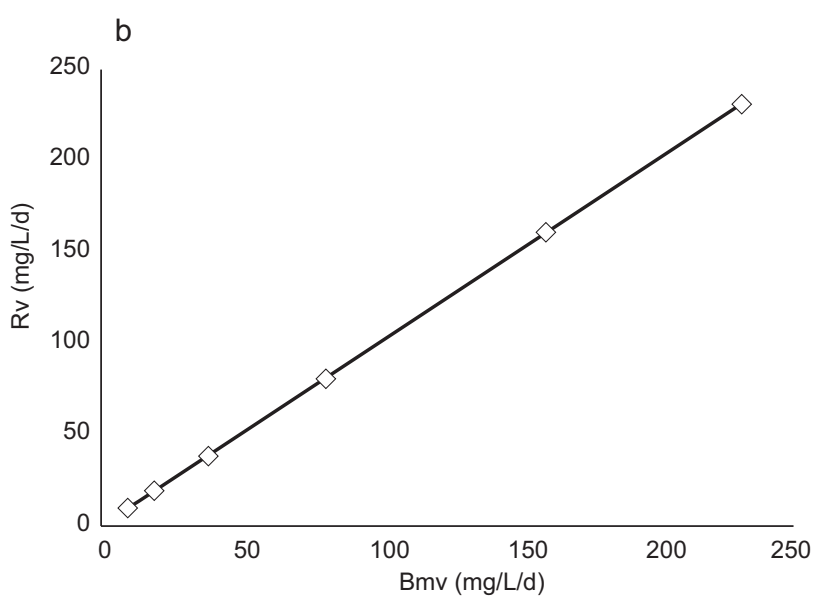

Fig. 6. Velocidad volumétrica de remoción de los herbicidas (Rv) en función de la carga volumétrica (Bvm) de los diferentes flujos de alimentación en la biobarrera. a) Cuantificación por cromatografía de líquidos de alta resolución (HPLC); b) Cuantificación por demanda química de oxígeno (DQO); c) Velocidad de generación $(\mathrm{Rvg})$ teórica $(\diamond)$ y experimental $(\boldsymbol{\nabla})$ de ácido cianúrico en función de la carga volumétrica del ácido cianúrico (Bacv) generado durante el cultivo continuo en la biobarrera. tercera reacción de la vía, se pudo detectar sólo en el género Arthrobacter, lo que pudiera explicar su presencia en la comunidad original, en el efluente y en la biota inmovilizada. El gen atzD que codifica a la enzima que hidroliza el último intermediario cíclico más recalcitrante en la vía de degradación, el ácido cianúrico, se encontró en el género Pseudomonas, donde se describió por primera vez la mineralización de atrazina y la presencia de los genes atzABCD (Maldelbum et al. 1995). El gen $a t z D$ también está presente en el género Cryseobacterium, género reportado con la capacidad de crecer en ácido cianúrico (Sandoval-Carrasco et al. 2013).

\section{DISCUSIÓN}

En el cultivo por lote semicontinuo se removieron completamente tanto la atrazina como la ametrina. La tasa de transformación, de acuerdo con el modelo de desintegración de primer orden, se ha calculado para 
CUADRO III. INTEGRANTES DE LA COMUNIDAD MICROBIANA INMOVILIZADA EN LA BIOBARRERA Y LOS GENES DETECTADOS EN CADA UNO DE ELLOS QUE CODIFICAN A LAS ENZIMAS QUE DEGRADAN HERBICIDAS S-TRIAZÍNICOS

\begin{tabular}{|c|c|c|c|c|c|c|c|}
\hline Microorganismo más cercano & Clave de acceso & $\operatorname{atz} A$ & $a t z B$ & $a t z C$ & $A t z D$ & $\operatorname{trz} D$ & $\operatorname{trz} N$ \\
\hline Chryseobacterium sp. & AB164636.1 & - & + & - & + & - & + \\
\hline Pseudomonas sp. & KF544922.1 & - & + & - & - & - & - \\
\hline Microbacterium sp. & JF344334.1 & - & + & - & - & - & + \\
\hline Pseudomonas nitroreducens & KC355311.1 & - & + & - & + & - & + \\
\hline Arthrobacter sp. & KC192787.1 & + & + & + & - & - & + \\
\hline Pseudomonas sp. & KC857485.1 & + & + & - & - & - & + \\
\hline Pseudomonas pseudoalcaligenes & KM349371.1 & - & + & - & - & + & + \\
\hline Paenibacillus sp. & DQ522166.1 & - & + & - & - & - & + \\
\hline Azospirillum sp. & AF411852.1 & - & + & - & - & - & + \\
\hline Citrobacter sp. & HO696465.1 & - & + & - & - & - & + \\
\hline Pseudomonas sp. & DO180954.1 & - & + & - & - & - & + \\
\hline
\end{tabular}

la atrazina de hasta $108 \mathrm{~d}$ en suelo, $72 \mathrm{~d}$ en humedales y 14 d en suelos adaptados (Gordon y Crumpton 1998, Webb et al. 2011). Para el caso de la ametrina se tienen datos de una vida media de $62 \mathrm{~d}$ en suelo y de $10.2 \mathrm{~h}$ utilizando un fotoreactor (TOXNET 2017). La vida media de los herbicidas durante los últimos ciclos del cultivo por lote semicontinuo fue de $1 \mathrm{~h}$ para ambos. Este valor y los obtenidos desde los primeros ciclos son considerablemente menores que los reportados y puede notarse una disminución en la vida media de los triazínicos conforme transcurre el número de ciclos. De igual forma, las velocidades volumétricas de remoción de ambos herbicidas se fueron incrementando al transcurrir el número de ciclos. Lo que indica que la comunidad microbiana se fue aclimatando y mantuvo la estabilidad para degradar eficientemente la ametrina y la atrazina en el sistema.

A pesar de tener una eficiencia de remoción del $100 \%$ para ambos herbicidas, la máxima eficiencia de remoción de la DQO fue de $85.41 \pm 5.58 \%$. Lo que puede indicar que otros compuestos de la formulación comercial, como surfactantes o coadyuvantes, no están siendo completamente metabolizados por la comunidad, o bien que hay productos metabólicos que se están acumulando. De igual forma, en el cultivo continuo con células en suspensión, la remoción de la DQO no alcanza el $100 \%$.

Al determinar la concentración de los herbicidas por HPLC se observó en los cromatogramas obtenidos la desaparición de los picos correspondientes a los herbicidas. Aunque invariablemente apareció un nuevo pico que corresponde al ácido cianúrico, último intermediario cíclico en la vía de degradación de los triazínicos. Cuando se comparó la velocidad de formación de ácido cianúrico con la es- tequiométricamente esperada, se observó un consumo parcial del intermediario. La velocidad de consumo del ácido cianúrico estaría dada por la diferencia de velocidades de generación teórica y experimental.

Durante el cultivo continuo la biopelícula adherida a las paredes del reactor que se fue incrementando a lo largo del tiempo (Fig. 4) pudo haber favorecido la elevada velocidad de remoción que se alcanzó en el sistema, ya que los microorganismos congregados en biopelículas (sésiles) presentan muchas ventajas en comparación con las células libres (planctónicas). Proporcionan, entre otras cosas, una estructura beneficiosa, posibilidad de nutrientes e intercambio genético entre los microorganismos participantes, así como protección del ambiente circundante en relación con, por ejemplo, la depredación y el estrés químico (Edwards y Kjellerup 2013). Se ha demostrado que, en sitios muy contaminados, las células crecen predominantemente en forma de biopelículas, para protegerse de las condiciones ambientales adversas (Gross et al. 2007). La formación de estas biopelículas es una característica natural de estos microorganismos y por lo tanto la robustez de estas estructuras puede emplearse para desarrollar estrategias de biorremediación eficientes, in situ (aguas subterráneas y otros sistemas acuáticos) o ex situ, utilizando reactores de biopelícula.

Cuando se evaluó la degradación de los triazínicos en cultivo por lote semicontinuo, utilizando un reactor de biopelícula (biobarrera), se obtuvieron eficiencias de remoción de la DQO del $100 \%$ para todos los ciclos, lo que nos indica que se están degradando los herbicidas, así como coadyuvantes y otros compuestos que forman parte de la presentación comercial. Sin embargo, la acumulación del intermediario ácido 
cianúrico fue detectado por HPLC, lo que confirma que su concentración no puede ser eficientemente medida por el método para la determinación de la DQO, debido a la naturaleza recalcitrante para la oxidación química de los compuestos que como el ácido cianúrico, incluyen en su molécula el anillo triazínico (APHA 1998).

Cuando se compara la eficiencia de remoción de la DQO, obtenida utilizando la biobarrera, con los resultados obtenidos con células en suspensión, la ventaja del sistema con la biota inmovilizada es indudable. Esto puede atribuirse a que la biobarrera permite una mayor concentración de microorganismos en el sistema, $1.11 \times 10^{11} \mathrm{UFC} / \mathrm{mL}$, comparada con la concentración de $1.48 \times 10^{9} \mathrm{UFC} / \mathrm{mL}$ alcanzada en el sistema con células planctónicas. Adicionalmente, la formación de la biopelícula protegió a la comunidad microbiana de cambios ambientales y del impacto de la concentración de los xenobióticos, permitiendo la degradación de los herbicidas aún con flujos altos de alimentación. Además de que el metabolismo característico de las bacterias dentro de la comunidad de la biopelícula es distinto al de las mismas bacterias que crecen en forma planctónica (Davey y O'toole 2000).

De los microorganismos cultivables predominantes que se encontraban inmovilizados en la biobarrera (Cuadro III), cinco de los aislados se identificaron como pertenecientes al género Pseudomonas, género reportado como degradador de diversos xenobióticos, entre ellos los herbicidas triazínicos (Mandelbum et al. 1995, De Souza et al. 1998, Cai et al. 2003). Otro de los géneros identificados fue Paenibacillus, reportado como degradador de los herbicidas hexazinona y tebuthiuron (Mostafa y Helling 2003). En la biobarrera vuelve a predominar el género Arthrobacter, que se encontraba en la comunidad original, aparecen el género Chryseobacterium, el cual ha sido reportado como un fuerte promotor para la formación de biopelícula (BurmØlle et al. 2007) y el género Microbacterium capaz de degradar hexazinona (Mostafá y Helling 2003) y prometrina (Pérez-Bárcena et al. 2014). Este género, al igual que el género Arthrobacter pueden degradar el intermediario ácido cianúrico (Shiomi y Ako 2012, Hatakeyama et al. 2015). No se han encontrado referencias del género Azospirillum en la degradación de compuestos triazínicos.

\section{CONCLUSIONES}

Aunque se lograron altas eficiencias de remoción de los herbicidas atrazina y ametrina usando cultivos con células planctónicas, la más alta eficiencia de remoción de la DQO obtenida fue del $89.29 \pm 0.02 \%$, en el cultivo continuo. El sistema con la biota inmovilizada en la biobarrera permitió la completa remoción de la DQO, lo que indicó remoción de coadyuvantes presentes en el herbicida comercial y productos metabólicos, con excepción del ácido cianúrico, cuya determinación por HPLC reveló altas eficiencias de remoción del intermediario de hasta el $87.02 \pm 0.21 \%$, mejorando la eficiencia obtenida por otros investigadores durante la degradación de herbicidas s-triazínicos. El género Pseudomonas es importante en la degradación de los herbicidas triazínicos ya que se detectó en la comunidad inicial, en el efluente y en el soporte. Todos los genes involucrados en la degradación de los s-triazínicos en la comunidad se pudieron detectar por PCR.

\section{REFERENCIAS}

APHA (1998). Standard methods for the examination of water and wastewater. 20a ed. American Public Health Association. Washington, EUA, 1325 pp.

BurmØlle M., Hansen L.H. y SØrensen S.J. (2007). Establishment and early succession of a multispecies biofilm composed of soil bacteria. Microb. Ecol. 54 (2), 352-362. DOI: 10.1007/s00248-007-9222-5

Cai B., Han Y., Liu B., Ren Y. y Jiang S. (2003). Isolation and characterization of an atrazine-degrading bacterium from industrial wastewater in China. Lett. Appl. Microbiol. 36 (5), 272-276.

DOI: $10.1046 / \mathrm{j} .1472-765 X .2003 .01307 . x$

Davey M.E. y O’toole G.A. (2000). Microbial biofilms: from ecology to molecular genetics. Microbiol. Mol. Biol. Rev. 64 (4), 847-867.

DOI: 10.1128/MMBR.64.4.847-867.2000

De Souza M.L., Newcombe D., Alvey S., Crowley D.E., Hay A., Sadowsky M. J. y Wackett L.P. (1998). Molecular basis of a bacterial consortium: interspecies catbolism of atrazine. Appl. Environ. Microbiol. 64 (1), 178-184.

Desai S.G. (2015). Continuous and semi-continuous cell culture for production of blood clotting factors. J. Biotechnol. 213 (10), 20-27.

DOI: 10.1016/j.jbiotec.2015.02.021

Domínguez-Garay A., Boltes K. y Esteve-Núñez A. (2016). Cleaning-up atrazine-polluted soil by using microbial electroremediating cells. Chemosphere 161, 365-371. DOI: 10.1016/j.chemosphere.2016.07.023

Edwards S.J. y Kjellerup B.V. (2013). Applications of biofilms in bioremediation and biotransformation of persistent organic pollutants, pharmaceuticals/personal care products, and heavy metals. Appl. Microbiol. 
Biotechnol. 97 (23), 9909-9921.

DOI: $10.1007 / \mathrm{s} 00253-013-5216-\mathrm{z}$

Felske A., Engelen B., Nübel U. y Backhaus H. (1996). Direct ribosome isolation from soil to extract bacterial rRNA for community analysis. Appl. Environ. Microbiol. 62 (11), 4162-4167.

Galíndez-Nájera S.P., Llamas-Martínez M.A., Ruiz-Ordaz N., Juárez-Ramírez C., Mondragón-Parada M.E., Ahuatzi-Chacón D. y Galíndez-Mayer J. (2009). Cyanuric acid biodegradation by a mixed bacterial culture of Agrobacterium tumefaciens and Acinetobacter sp in a packed bed biofilm reactor. J. Ind. Microbiol. Biotechnol. 36 (2), 275-284.

DOI: $10.1007 /$ s 10295-008-0496-5

Galíndez-Nájera S.P., Ramos-Monroy O., Ruiz-Ordaz N., Salmerón-Alcocer A., Juárez-Ramírez C., AhuatziChacón D., Curiel-Quesada E. y Galíndez-Mayer J. (2011). Simultaneous degradation of atrazine and simazine by a binary culture of Stenotrophomonas maltophilia and Arthrobacter sp. in a two-stage biofilm reactor. J. Chem. Technol. BIotechnol. 86 (4), 554-561. DOI: $10.1002 /$ jctb. 2550

Gordon G.L. y Crumpton G.W. (1998). Distribution and environmental fate of pesticides in prairie wetlands. Great Plains Res. 8, 73-95.

Gross R., Hauer B., Otto K. y Schmid A. (2007). Microbial biofilms: New catalysts for maximizing productivity of long-term biotransformations. Biotechnol. Bioeng. 98 (6), 1123-1134. DOI: 10.1002/bit.21547

Hach (2012). Water analysis handbook. 7a ed. Hach Company. Loveland, Colorado, EUA, 1641 pp.

Hansen A.M., Treviño-Quintanilla L.G., Márquez-Pacheco H., Villada-Canela M., González-Márquez L.C., Guillén-Garcés R.A. y Hernández-Antonio A. (2013). Atrazina: un herbicida polémico. Rev. Int. Contam. Ambie. 29, 65-84.

Harada N. (2007). Biodegradation of s-triazine herbicides by soil microorganisms and their application for in situ bioremediation. Bull. Facul. Agric. Niigata. Univ. 60, 1-7.

Hatakeyama T., Takagi K., Yamazaki K., Sakakibara F., Ito K., Takasu E., Naokawa T. y Fujii K. (2015). Mineralization of melamine and cyanuric acid as sole nitrogen source by newly isolated Arthrobacter spp. using a soil-charcoal perfusión method. Word. J. Mircobiol. Biotechnol. 31 (5), 785-793.

DOI: $10.1007 /$ s11274-015-1832-3

IRET (2018). Manual de Plaguicidas de Centroamérica. Instituto Regional de Estudios de Sustancias Tóxicas [en línea]. http://www.plaguicidasdecentroamerica. una.ac.cr/index.php/ingredientes-activos 13/05/2018

Jacobsen C.S., Shapir N., Jensen L.O., Jensen E.H., Juhler R.K., Streibig J.C., Mandelbaum R.T. y Helweg A. (2001). Bioavailability of triazine herbicides in a Sandy soil profile. Biol. Fertil. Soils. 33 (6), 501-506.

DOI: $10.1007 / \mathrm{s} 003740100359$

Jacomini A.E., De Camargo P.B., Avelar W.E. y Bonato P.S. (2011). Assessment of ametryn contamination in river water, river sediment, and mollusk bivalves in São Paulo state, Brazil. Arch. Environ. Contam. Toxicol. 60 (3), 452-461. DOI: 10.1007/s00244-010-9552-z

Kontchou C.Y. y Gschwind N. (1999). Biodegradation of s-triazine compounds by a stable mixed bacterial community. Ecotoxicol Environ. Saf. 43 (1), 47-56. DOI: 10.1006/eesa.1998.1756

Kucka M., Pogrmic-Majkic K., Fa S., Stojilkovic S.S. y Kovacevic R. (2012). Atrazine acts as an endocrine disrupter by inhibiting cAMP-specific phosphodiesterase-4. Toxicol. Appl. Pharmacol. 265 (1), 19-26. DOI: 10.1016/j.taap.2012.09.019

Mandelbaum R.T., Allan D.L. y Wackett L.P. (1995). Isolation and characterization of a Pseudomonas $\mathrm{sp}$ that mineralizes the s-triazine herbicide atrazine. Appl. Environ. Microbiol. 61 (4), 1451-1457.

Mostafa F.I.y Helling C.S. (2003). Isolation and 16S DNA characterization of soil microorganisms from tropical soils capable of utilizing the herbicides hexazinone and tebuthiuron. J. Environ. Sci. Health. B. 38 (6), 783-797. DOI: 10.1081/PFC-120025579

Nishimura K., Yamamoto M., Nakagomi T., Takiguchi Y., Naganuma T. y Uzuka Y. (2002). Biodegradation of triazine herbicides on polyvinylalcohol gel plates by the soil yeast Lipomyces starkeyi. Appl. Microbiol. Biotechnol. 58 (6), 848-852. DOI: $10.1007 / \mathrm{s} 00253-002-0950-7$

Nissim S., Yeshayahu N., Yakov L. y Rivka C. (2014). Atrazine biodegradation by a monoculture of Raoultella planticola isolated from a herbicides wastewater treatment facility. Int. Biodeter. Biodegr. 92, 6-11.

DOI: 10.1016/j.ibiod.2014.04.003

Olea I. L., Sabaté S. y Vinciguerra H. (2009). Manejo de malezas. Herramientas para el control químico. Capítulo 10. Manual del cañero [en línea]. http:// www.eeaoc.org.ar/publicaciones/categoria/18/61/ MC-Manejo-de-malezas---cap-10.html 30/01/2018.

Pérez-Bárcena J.F., Ahuatzi-Chacón D., Castillo-Martínez K.L., Ruiz-Ordaz N., Galíndez-Mayer J., JuárezRamírez C. y Ramos-Monroy O. (2014). Effect of herbicide adjuvants on the biodegradation rate of the methylthiotriazine herbicide prometryn. Biodegradation 25 (3), 405-415. DOI: $10.1007 / \mathrm{s} 10532-013-9669-7$

Pussemier L., Goux S., Vanderheyden V., Debongnie P.1., Tresinie I. y Foucart G. (1997). Rapid dissipation of atrazine in soils taken from various maize fields. Weed Res. 37 (3), 171-179. DOI: 10.1046/j.1365-3180.1997.d01-18.x 
Ralebitso T.K., Senior E. y Van Versevld H.W. (2002). Microbial aspects of atrazine degradation in natural environments. Biodegradation 13 (1), 11-19.

DOI: $10.1023 / \mathrm{A}: 1016329628618$

Rimayi C., Odusanya D., Weiss J.M., Boer J., Chimuka L. y Mbajiorgu F. (2018). Effects of environmentally relevant sub-chronic atrazine concentrations on African clawed frog (Xenopus laevis) survival, growth and male gonad development. Aquat. Toxicol. 199, 1-11. DOI: $10.1016 / j$.aquatox.2018.03.028

Rousseaux S., Hartmann A. y Soulas G. (2001). Isolation and characterization of new gram-negative and grampositive atrazine degrading bacteria from different French soils. FEMS Microbiol. Ecol. 36 (2-3), 211222. DOI: 10.1016/S0168-6496(01)00135-0

Sánchez-Sánchez R., Ahuatzi-Chacón D., Galíndez-Mayer J., Ruiz-Ordaz N. y Salmerón-Alcocer A. (2013). Removal of triazine herbicides from aqueous systems by a biofilm reactor continuously or intermittently operated. J. Environ. Manage. 128, 421-426.

DOI: $10.1016 /$ j.jenvman.2013.05.050

Sandoval-Carrasco C., Ahuatzi-Chacón D., GalíndezMayer J., Ruiz-Ordaz N., Juárez-Ramírez C. y Martínez-Jerónimo F. (2013). Biodegradation of a mixture of the herbicides ametryn, and 2,4-dichlorophenoxyacetic acid (2,4-D) in a compartmentalized biofilm reactor. Bioresource Technol. 145, 33-36.

DOI: 10.1016/j.biortech.2013.02.068

Sattin M. y Berti A. (2004). Parámetros para la competencia malezas-cultivos. Organización de las Naciones Unidas para la Agricultura y la Alimentación. [en linea]. http://www.fao.org/docrep/007/y5031s/y5031s04. htm\#bm04 15/01/2018.

Shapir N., Mongodin E.F., Sadowsky M.J., Daugherty S.C., Nelson K.E. y Wackett L.P. (2007). Evolution of catabolic pathways: genomic insights into microbial s-triazine metabolism. J. Bacteriol. 189 (3), 674-682. DOI: 10.1128/JB.01257-06

Shiomi N. y Ako M. (2012). Biodegradation of melamine and cyanuric acid by a newly-isolated Microbacterium strain. Adv. Microbiol. 2 (3), 303-309.

DOI: 10.4236/aim.2012.23036

Singh S., Kumar V., Chauhan A., Datta S., Wani A.B., Singh N. y Singh J. (2018). Toxicity, degradation and analysis of the herbicide atrazine. Environ. Chem. Lett. 16 (1), 211-237. DOI: 10.1007/s10311-017-0665-8

SSA (2000). Modificación a la Norma Oficial Mexicana NOM-127-SSA1-1994. Salud ambiental. Agua para uso y consumo humano. Límites permisibles de calidad $\mathrm{y}$ tratamientos a que debe someterse el agua para su potabilización. Secretaría de Salud. Diario Oficial de la Federación. 20 de junio de 2000.
Strong L.C., Rosendahl C., Johnson G., Sadowsky M.J. y Wackett L.P. (2002). Arthrobacter aurescens TC1 metabolizes diverse s-triazine ring compounds. Appl. Environ. Microbiol. 68 (12), 5973-5980.

DOI: 10.1128/AEM.68.12.5973-5980.2002

Sun J.T., Pan L.L., Zhan Y., Tsang D.C.W. y Zhu L.Z. (2017). Atrazine contamination in agricultural soils from the Yangtze river delta of China and associated health risks. Environ. Geochem. Hlth. 39 (2), 369-378. DOI: $10.1007 / \mathrm{s} 10653-016-9853-\mathrm{x}$

Tafoya-Garnica A., Macías-Flores A., Ruiz-Ordaz N., Juárez-Ramírez C. y Galíndez-Mayer J. (2009). Kinetics of atrazine biodegradation by suspended and immobilized mixed microbial cells cultivated in continuous systems. J. Chem. Technol. Biotechnol. 84 (7), 982-991. DOI: $10.1002 /$ jctb.2121

TOXNET (2017). Ametryne. Toxicology Data Network [en línea]. https://toxnet.nlm.nih.gov/cgi-bin/ sis/search/a?dbs+hsdb:@term+@DOCNO+1710 05/02/2017.

USEPA (2003). EPA 738-R-04-004. Interim Reregistration Eligibility Decision (IRED) for Atrazine, CASE 0062, United States Environmental Protection Agency. Document. Washington, D.C., EUA, 287 pp.

USEPA (2005). EPA 738-R-05-006. Reregistration Eligibility Decision (RED) for Ametryn. (2-ethylamino)4-(isopropylamino)-6-(methylthio)-s-triazine, CASE 2010, United States Environmental Protection Agency. Document. Washington, D.C., EUA, 47 pp.

Victores S., Castillo A., Faife E., Rabasa Y., Rodríguez Y., Rojas L.E., Palacios J. y Figueredo A. (2008). Cultivos semicontinuos como una herramienta para la caracterización celular del hibridoma murino 1E10. Biotecnología Aplicada 25, 149-154.

Webb M.T.R., Sandstrom W.M., Krutz J.L. y Shaners L.D. (2011). Simulation of branched serial first-order decay of atrazine and metabolites in adapted and nonadapted soils. Environ. Toxicol. Chem. 30 (9), 1973-1981.

DOI: $10.1002 /$ etc.597

WHO (2011). Atrazine and its metabolites in drinking-water. Background document for development of WHO Guidelines for Drinking-water Quality. Who Press, World Health Oraganization. Ginebra, Suiza, 23 pp.

Yu J., He H., Yang W.L., Yang Ch., Zeng G. y Wu X. (2018). Magnetic bionanoparticles of Penicillium sp. yz11-22N2 doped with $\mathrm{Fe}_{3} \mathrm{O}_{4}$ and encapsulated within PVA-SA gel beads for atrazine removal. Bioresour. Technol. 260, 196-203.

DOI: $10.1016 /$ j.biortech.2018.03.103 